\title{
Measuring the Pressure in the Superficial Inferior Epigastric Vein to Monitor for Venous Congestion in Deep Inferior Epigastric Artery Perforator Breast Reconstructions: A Pilot Study
}

\author{
Jeroen M. Smit, M.D., ${ }^{1,2}$ Thorir Audolfsson, M.D., ${ }^{1}$ lain S. Whitaker, \\ B.A. (Hons.), M.A. Cantab, M.B.B.Chir., M.R.C.S., ${ }^{3}$ Paul M.N. Werker, M.D., Ph.D., ${ }^{4}$ \\ Rafael Acosta, M.D., E.B.O.Pras., ${ }^{1}$ and Anders G. Liss, M.D., Ph.D.'
}

During deep inferior epigastric artery perforator (DIEP) flap dissection, we noted that in many cases the superficial vein on the ipsilateral side of the flap was engorged and tense, and in others, it was empty. This led us to believe that the pressure is increased as the result of preferential outflow through the superficial vein in some cases, which could result in venous congestion of the flap if this vessel was not anastomosed. To test this hypothesis, we measured the venous pressure in the superficial venous system before and after flap dissection. The pressure in the superficial inferior epigastic vein of a DIEP flap was measured in 26 consecutive flaps to investigate the correlation between the pressure and venous congestion of the flap. The first measurement was performed at the beginning of the dissection, and the second measurement was taken after the flap had been completely raised on a single perforator. The mean increase in pressure after flap dissection was $10.6 \mathrm{~mm} \mathrm{Hg}(\mu=10.6$; range -1 to $31 ; \mathrm{O} \pm 7.0 \mathrm{~mm} \mathrm{Hg})$. Clinical signs of venous congestion were observed in one case. In this case, the increase in venous pressure was with $31 \mathrm{~mm} \mathrm{Hg}$, also the highest. Although the results of this report are preliminary, they indicate that the pressure in the superficial vein of DIEP flaps might be of predictive value for venous congestion.

KEYWORDS: Venous congestion, venous pressure, superficial inferior epigastric vein, microvascular breast reconstruction, deep inferior epigastric perforator flap

${ }^{1}$ Department of Plastic and Reconstructive Surgery, Uppsala University Hospital, Uppsala, Sweden; ${ }^{2}$ Department of Plastic and Reconstructive Surgery, Catharina Hospital Eindhoven, Eindhoven, The Netherlands; ${ }^{3}$ Department of Plastic and Reconstructive Surgery, Welsh Centre for Burns and Plastic Surgery, Morriston Hospital, Swansea, United Kingdom; ${ }^{4}$ Department of Plastic and Reconstructive Surgery, University Medical Center Groningen, Groningen, The Netherlands.

Address for correspondence and reprint requests: Anders G. Liss, M.D., Ph.D., Department of Plastic and Reconstructive Surgery,
Uppsala University Hospital, SE-751 85 Uppsala, Sweden (e-mail: jermasmit@gmail.com; info@lissliss.se).

J Reconstr Microsurg 2010;26:103-108. Copyright (C) 2010 by Thieme Medical Publishers, Inc., 333 Seventh Avenue, New York, NY 10001, USA. Tel: +1(212) 584-4662.

Received: April 21, 2009. Accepted after revision: September 9, 2009. Published online: December 10, 2009.

DOI: http://dx.doi.org/10.1055/s-0029-1243294.

ISSN 0743-684X. 
Since its introduction by Koshima and Soeda, ${ }^{1}$ the deep inferior epigastric artery perforator (DIEP) flap has developed into a reliable option in breast reconstructions. The flap provides a large bulk of autologous tissue, while maintaining minimal donor site morbidity. ${ }^{2-6}$

Despite the fact that the reliability of the flap has increased as the result of technical improvements over the last decade, ${ }^{7,8}$ complications still occur. One of these complications is venous congestion, which may occur when outflow of the flap through the perforator vein is insufficient compared with the blood inflow. Venous congestion has been reported to occur in $5 \%$ of the flaps. ${ }^{8}$ This problem usually can be solved by creating an additional venous drainage, using the superficial epigastric vein. ${ }^{9,10}$

Accurate assessment of the perfusion of free tissue transfers has always been a challenge for surgeons undertaking microvascular reconstructive procedures, and there are a range of contemporary techniques in clinical use and currently in development. ${ }^{11}$ It is well recognized that surgical experience is an important predictor for flap survival, ${ }^{12}$ and recent advances in technology and improvements in surgical technique have led to reported success rates between 95 and 98\%. ${ }^{13,14}$ Taking into account that DIEP flaps are considered as time-consuming and complex procedures with inherent risks and psychological ramifications to the patient, it is crucial to optimize chances of a successful outcome.

Clinical tests used to detect venous congestion such as inspection (to assess color), palpation (to assess turgor and temperature), and capillary refill of the flap are still commonly used, ${ }^{15,16}$ although animal tests have shown that change in color and increased refill are relatively late signs of venous congestion. ${ }^{17}$ Because these tests often only becomes positive after the microsurgical anastomosis is completed, this potentially increases operative times.

Adjunctive techniques used to monitor flaps postoperatively include near-infrared spectroscopy, ${ }^{18-20}$ indocyanine-green fluorescence video angiography, ${ }^{21}$ simultaneous noninvasive laser Doppler flowmetry and tissue spectrophotometry, ${ }^{22}$ and modified oxygen microelectrode combined with laser Doppler flowmetry. ${ }^{17}$

At the end of the DIEP flap dissection, we noted that in many cases the superficial vein on the ipsilateral side of the flap was engorged and tense, and in others, it was empty. This led us to believe that the pressure might be increased in some cases and could eventually result in venous congestion. To test this hypothesis, we measured the venous pressure in the superficial venous system before and after flap dissection.

\section{MATERIALS AND METHODS}

\section{Design of Study}

The venous pressure in the ipsilateral superficial inferior epigastic vein (SIEV) of a DIEP flap was measured in 26 consecutive flaps. The first measurement was performed at the beginning of the dissection of the flap and was regarded as the normal pressure in the superficial venous system. The second measurement was taken after the dissection of the flap had been completed and the flap was raised on a single deep inferior epigastric perforator.

To investigate if there was a correlation between the change in pressure and venous congestion, the flaps were evaluated during surgery (prior to pedicle division and after the microsurgical anastomosis was completed) as well as a week postoperatively for any signs of venous congestion. The pressure measurements of the SIEV were only performed during surgery, so no measurements were performed during the postoperative checkups.

Because this is a pilot study, the criteria used to connect the superficial system to the cephalic vein were any sign of venous congestion or a caliber of $1.5 \mathrm{~mm}$ or larger of the SIEV. The results of our measurements did not influence this decision.

Preoperative computer tomographic angiography was performed to decide which perforator was best suited to base the flap on.

\section{Patient Characteristics}

The age, sex, indication for surgery, American Society of Anesthesiologists (ASA) classification, nicotine use, received radiotherapy, type of anastomosis, receiving vessels, ischemia time, anastomotic time, surgery time, need of a revision, and surgical outcome of all patients were noted.

The study included 20 unilateral and three bilateral reconstructions. The age of the patients included ranged from 38 to 63 years $(\mu=50 ; O=6.0)$. The ASA classification ranged from one to three $(\mu=2)$. Two patients were treated for hypertension. No patients used corticosteroids or had cardiovascular problems or diabetes mellitus. None of the patients smoked during admission for surgery, and 54\% of patients received preoperative radiotherapy. All breast reconstructions were for oncological reasons, with four immediate breast reconstructions and 22 delayed reconstructions.

The internal mammary artery was the recipient site in the majority of cases $(n=24)$. The circumflex scapular artery was the recipient vessel in two cases $(\mathrm{n}=2)$. The respective vein was used for the venous anastomosis. All arterial and venous anastomoses were done in an end-to-end fashion. In five flaps, a second venous anastomosis was performed as the diameter of 
Table 1 Patient Demographics and Variables of the 26 Flaps Used for This Research

\begin{tabular}{ll}
\hline Mean age (y) (SD) & 50, range 38-63 (6.0) \\
Mean ASA classification & 2, range 1-3 \\
Number of uni- and bilateral & $20 / 3$ \\
$\quad$ reconstructions & $4 / 22$ \\
Number of primary and & \\
$\quad$ secondary reconstructions & \\
\hline ASA, American Society of Anesthesiologists; SD, standard deviation.
\end{tabular}

the SIEV was $1.5 \mathrm{~mm}$ or larger, and in one case, signs of venous congestion were observed. The cephalic vein was used in all cases as the recipient vessel for the secondary anastomosis. The mean ischemia time was just under 1 hour ( $\mu=56$; range 31 to $160 ; O$ Ó 26 minutes). The mean anastomotic time was 14 minutes $(\mu=14$; range 7 to 28 ; Ó \pm 6 minutes) and 8 minutes $(\mu=8$; range 2 to 23 ; $\mathrm{O} \pm 5$ minutes) for the artery and vein, respectively. The mean operative time was 6 hours and 6 minutes ( $\mu=366$; range 210 to 510 ; Ó \pm 79 minutes). There were no flap losses, either partial or complete (overall success rate $100 \%$; Table 1 ).

\section{Venous Pressure Measurement}

To measure the pressure in the SIEV, a 22-gauge venflon (Becton Dickinson, Helsingborg, Sweden) was connected to a disposable pressure transducer (Becton Dickinson). The tip of the venflon was inserted into the vein, which had been isolated, securing the vein around it by gentle manipulation of the hand. After the tip was inserted, the microvascular clamp (S\&T, Neuhausen, Switzerland) was removed and the pressure was measured (see Fig. 1).

\section{RESULTS}

Of the 26 flaps used for this study, the pressure in the ipsilateral SIEV could be measured in 25 . In one case, the pressure could not be measured as the caliber of the vein was too small to allow insertion of the cannula.

\section{Venous Pressure Measurements}

The mean pressure in the SIEV at the start of flap dissection was $2.2 \mathrm{~mm} \mathrm{Hg}(\mu=2.2$; range $0-4$; $\mathrm{O} \pm 1.1 \mathrm{~mm} \mathrm{Hg}$ ). The mean pressure after completion

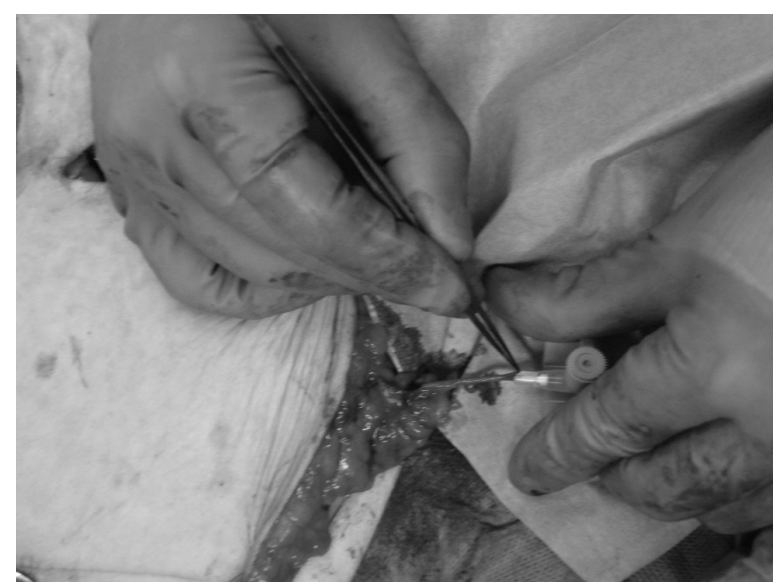

Figure 1 The tip of the venflon inserted into the superficial inferior epigastic vein, which had been isolated. The vein is being manipulated around the tip of the venflon using microsurgical forceps.

of flap dissection was $12.8 \mathrm{~mm} \mathrm{Hg}$ ( $\mu=12.8$; range 0 to 32; $\mathrm{O} \pm 6.8 \mathrm{~mm} \mathrm{Hg}$ ). The mean increase in pressure after flap dissection was $10.6 \mathrm{~mm} \mathrm{Hg} \quad(\mu=10.6$; range -1 to 31 ; Ó $\pm 7.0 \mathrm{~mm} \mathrm{Hg}$; Table 2 ).

Clinical signs of venous congestion were observed in one case out of the 26 (4\%). In this case, the increase in venous pressure was also the highest, $31 \mathrm{~mm} \mathrm{Hg}$. At the time of this measurement, no signs of congestion were visible. The clinical signs (increasing turgor, delayed capillary refill, blue coloration) became apparent 10 minutes after the pressure in the SIEV was measured. In this case, the superficial vein was anastomosed to the cephalic vein to augment venous outflow of the flap. After the superficial vein was anastomosed, the signs of venous congestion resolved. In one case, the pressure in the SIEV decreased to 0 . In the other cases, the pressure increased without clinical signs of venous congestion, either during surgery or postoperatively. No differences were seen in the increased pressure between the unilateral and bilateral reconstructions.

\section{DISCUSSION}

This study was undertaken to try to find a simple, accurate, and objective method to measure the pressure in the superficial system to identify those at risk of venous congestion that requires an additional venous anastomosis. We describe a simple technique using a

Table 2 The Mean Pressure in the Superficial Inferior Epigastric Vein prior to and after Flap Dissection

\begin{tabular}{llll}
\hline & $\begin{array}{l}\text { Prior to Flap } \\
\text { Dissection }(\mathbf{n}=\mathbf{2 5}) *\end{array}$ & $\begin{array}{l}\text { After Flap } \\
\text { Dissection }(\mathbf{n}=\mathbf{2 5})^{*}\end{array}$ & $\begin{array}{l}\text { Difference } \\
(\mathbf{n}=\mathbf{2 5}) *\end{array}$ \\
\hline Mean pressure $\left(\mathrm{cm} \mathrm{H}_{2} \mathrm{O}\right)$ & 2.2 & 12.8 & 10.6 \\
Range $\left(\mathrm{cm} \mathrm{H}_{2} \mathrm{O}\right)$ & $0-4$ & $0-32$ & $-1-31$ \\
\hline
\end{tabular}

*In one case, no measurement was performed because of the minimal caliber of vein. 
22-gauge venflon connected to a disposable pressure transducer, which are both commonly used by anesthetists.

In our pilot study of 26 flaps, one episode of intraoperative venous congestion was observed. In this case, the increase of venous pressure after dissection was the highest at $31 \mathrm{~mm} \mathrm{Hg}$. After we had performed a second venous anastomosis (superficial epigastric vein to the cephalic vein), as expected, the signs of venous congestion resolved. In the case that read a pressure in the SIEV of 0 , there was an exceptionally large-caliber vein in the deep system. In the other cases where the pressure increased, no signs of venous congestion were observed either intra- or postoperatively.

In 1999, Villafane et $\mathrm{al}^{9}$ reported the importance of the superficial system. They used the SIEV as a lifeboat in a complicated case. After a thrombus formed twice in the deep inferior epigastric vein, it was no longer useable for drainage. The flap was saved by anastomosing the SIEV via a vein graft to the circumflex scapular vein. ${ }^{9}$ Blondeel et $\mathrm{al}^{10}$ investigated the SIEV in an anatomic study in 15 fresh cadavers and three abdominoplasty specimens and retrospectively reviewed 249 DIEP and 279 transverse rectus abdominal muscle microvascular breast reconstructions. They recommended using the SIEV if it is wider than $1.5 \mathrm{~mm}$ as secondary if not primary venous anastomoses. ${ }^{10}$ This was affirmed by other clinical and anatomic studies. ${ }^{18,23,24}$ Although this criterion is widely applied today, the diameter of the SIEV might not be an absolute predictor for venous congestion. A recent study did not show a direct correlation between vessel diameters of superficial and deep inferior epigastric systems, meaning the diameter of the SIEV can be relatively large, but the deep venous system is still large enough to drain the complete flap. $^{25}$

The advantage of the technique described in this article is that it offers direct information about the venous pressure in the superficial system and thus if the SIEV should be anastomosed or not. If the pressure is increased, the preparation for the second anastomosis can be made together with the preparation of the donor site, thus potentially saving operative time. Also, the results of this study indicate that the pressure in the SIEV rises before clinical signs of congestion are observed. This means that a possible complication can be acted on in an earlier phase, making the chance on severe complications smaller.

Because this is a pilot study, the results of this study need to be confirmed in a larger population, especially taking into consideration that in the current population venous congestion was observed only once. Apart from confirming our findings in a larger population, this pilot study also raises some questions among others about the redistribution of flow in a flap after harvest on the perforator vessels, for exam- ple, how the pressure will change after flap transfer and microsurgery and if the pressure will come back to the baseline after surgery. Also, the pressure in the contralateral SIEV could be of interest; in a unilateral reconstruction, for example, this might give an indication of the amount of flap that can be safely taken beyond the midline.

Compared with new monitoring techniques, the advantage of the described technique is that it is simple, inexpensive, and easy to use. The materials used to measure the venous pressure are commonly used by anesthesiologists and are therefore at hand. And because these materials are disposable, they do not need to be sterilized afterward or bagged before use.

\section{CONCLUSION}

Although the results of this report are preliminary, it indicates that the pressure in the superficial vein of DIEP flaps might be of predictive value for venous congestion. A study with a larger population needs to be performed to confirm the expectations this study brings forth.

\section{NOTES}

Presented at the Summer Scientific Meeting of the British Association of Plastic, Reconstructive and Aesthetic Surgeons, Deauville, France, July 4, 2007, and the Spring Scientific Meeting of the Dutch Association of Plastic Surgeons, Utrecht, The Netherlands, April 3, 2009.

\section{REFERENCES}

1. Koshima I, Soeda S. Inferior epigastric artery skin flaps without rectus abdominis muscle. Br J Plast Surg 1989;42: 645-648

2. Garvey PB, Buchel EW, Pockaj BA, et al. DIEP and pedicled TRAM flaps: a comparison of outcomes. Plast Reconstr Surg 2006;117:1711-1719; discussion 1720-1721

3. Nahabedian MY, Tsangaris T, Momen B. Breast reconstruction with the DIEP flap or the muscle-sparing (MS-2) free TRAM flap: is there a difference? Plast Reconstr Surg 2005;115:436-444; discussion 445-446

4. Chen CM, Halvorson EG, Disa JJ, et al. Immediate postoperative complications in DIEP versus free/musclesparing TRAM flaps. Plast Reconstr Surg 2007;120:14771482

5. Futter CM, Webster MH, Hagen S, Mitchell SL. A retrospective comparison of abdominal muscle strength following breast reconstruction with a free TRAM or DIEP flap. Br J Plast Surg 2000;53:578-583

6. Damen TH, Timman R, Kunst EH, Gopie JP, Bresser PJ, Seynaeve C, Menke-Pluijmers MB, Mureau MA, Hofer SO, Tibben A. High satisfaction rates in women after DIEP flap breast reconstruction. J Plast Reconstr Aesthet Surg 2008; November 24 (Epub ahead of print) 
7. Smit JM, Dimopoulou A, Liss AG, Zeebregts CJ, Kildal M, Whitaker IS, Magnusson A, Acosta R. Preoperative CT angiography reduces surgery time in perforator flap reconstruction. J Plast Reconstr Aesthet Surg 2009;62:1112-1117

8. Tran NV, Buchel EW, Convery PA. Microvascular complications of DIEP flaps. Plast Reconstr Surg 2007;119:13971405; discussion 1406-1408

9. Villafane O, Gahankari D, Webster M. Superficial inferior epigastric vein (SIEV): "lifeboat" for DIEP/TRAM flaps. Br J Plast Surg 1999;52:599

10. Blondeel PN, Arnstein M, Verstraete K, et al. Venous congestion and blood flow in free transverse rectus abdominis myocutaneous and deep inferior epigastric perforator flaps. Plast Reconstr Surg 2000;106:1295-1299

11. Sloan GM, Reinisch JF. Flap physiology and the prediction of flap viability. Hand Clin 1985;1:609-619

12. Sloan GM, Sasaki GH. Noninvasive monitoring of tissue viability. Clin Plast Surg 1985;12:185-195

13. Chen KT, Mardini S, Chuang DC, et al. Timing of presentation of the first signs of vascular compromise dictates the salvage outcome of free flap transfers. Plast Reconstr Surg 2007;120:187-195

14. Smit JM, Acosta R, Zeebregts CJ, Liss AG, Anniko M, Hartman EH. Early reintervention of compromised free flaps improves success rate. Microsurgery 2007;27:612-616

15. Jallali N, Ridha H, Butler PE. Postoperative monitoring of free flaps in UK plastic surgery units. Microsurgery 2005;25: 469-472

16. Whitaker IS, Gulati V, Ross GL, Menon A, Ong TK. Variations in the postoperative management of free tissue transfers to the head and neck in the United Kingdom. Br J Oral Maxillofac Surg 2007;45:16-18

17. Liss AG, Liss P. Use of a modified oxygen microelectrode and laser-Doppler flowmetry to monitor changes in oxygen tension and microcirculation in a flap. Plast Reconstr Surg 2000;105:2072-2078

18. Repez A, Oroszy D, Arnez ZM. Continuous postoperative monitoring of cutaneous free flaps using near infrared spectroscopy. J Plast Reconstr Aesthet Surg 2008;61: $71-77$

19. Cai ZG, Zhang J, Zhang JG, et al. Evaluation of near infrared spectroscopy in monitoring postoperative regional tissue oxygen saturation for fibular flaps. J Plast Reconstr Aesthet Surg 2008;61:289-296

20. Scheufler O, Exner K, Andresen R. Investigation of TRAM flap oxygenation and perfusion by near-infrared reflection spectroscopy and color-coded duplex sonography. Plast Reconstr Surg 2004;113:141-152; discussion 153-155

21. Holm C, Tegeler J, Mayr M, Becker A, Pfeiffer UJ, Mühlbauer W. Monitoring free flaps using laser-induced fluorescence of indocyanine green: a preliminary experience. Microsurgery 2002;22:278-287

22. Hölzle F, Loeffelbein DJ, Nolte D, Wolff KD. Free flap monitoring using simultaneous non-invasive laser Doppler flowmetry and tissue spectrophotometry. J Craniomaxillofac Surg 2006;34:25-33

23. Lundberg J, Mark H. Avoidance of complications after the use of deep inferior epigastric perforator flaps for reconstruction of the breast. Scand J Plast Reconstr Surg Hand Surg 2006; 40:79-81

24. Schaverien M, Saint-Cyr M, Arbique G, Brown SA. Arterial and venous anatomies of the deep inferior epigastric perforator and superficial inferior epigastric artery flaps. Plast Reconstr Surg 2008;121:1909-1919

25. Ayhan S, Oktar SO, Tuncer S, Yucel C, Kandal S, Demirtas Y. Correlation between vessel diameters of superficial and deep inferior epigastric systems: Doppler ultrasound assessment. J Plast Reconstr Aesthet Surg 2009;62:1140-1147 
